\title{
Test of IR-DSRC in Measuring Vehicle Speed for ITS Applications
}

\author{
Hyung Jin Kim ${ }^{1}$, Jin-Tae Kim² ${ }^{2}$ and Kee Yeon Hwang ${ }^{3}$ \\ ${ }^{1}$ Dept. of Urban Plan. and Eng., Yonsei Univ., Seoul, Korea \\ hyungkimeyonsei.ac.kr \\ ${ }^{2}$ Div. of Traffic Manag. and Planning, Seoul Metropolitan Police Agency, Korea \\ jtkim@dreamwiz.com \\ ${ }^{3}$ Dept. of Urban Plan. and Design, Hongik Univ., Seoul, Korea \\ keith@hongik.ac.kr
}

\begin{abstract}
Wireless communication technology has been introduced in the field of Intelligent Transportation Systems (ITS) in the past decades, and its applicability has been widely expending. Feasibility of the IR-DSRC based vehicle detection systems in measuring vehicle speed was tested as a possible alternative of the conventional inductive loop based systems requiring high construction and maintenance cost. It was found from the field test that the speed data from the IR-DSRC detection systems were statistically identical to the ones from the loop based systems at $95 \%$ confidence level.
\end{abstract}

\section{Introduction}

ITS has been highlighted in the past decades as possible solutions to resolve traffic congestion and to provide sophisticated information service to road users. Researches in the field of ITS have been robustly conducted in depth with diverse interests. Various ITS subsystems can be categorized depending upon their usability. Ones of the ITS subsystems highly recognized by users include Adaptive Traffic Control Systems (ATCS), Electrical Toll Collection Systems (ETCS), and Advanced Traveler Information Systems (ATIS). With their own scopes and interests, functionality of these systems has been extended. Applicability of their core technologies has been expanded. The boundaries of those ITS subsystems are recently being overlapped [1, 2].

It has been recognized in the field of ITS that a conventional loop based vehicle detection technology suffers for practical limitations in its reliability. Repetitive repairing and frequent constructions on some of urban highway sections has caused cutting of header and feather cables connecting loops to controllers. It makes the systems be in rest for a certain period and thus performance of ITS be ineffective. It also has a problem with data accuracy when a length of feather line becomes long [3]. A new technology enhancing stability and reliability of the vehicle detection systems for successful traffic surveillance is highly needed [4].

ETCS has been widely implemented in various cities and nations. It provides drivers with driving convenience at tollgate areas by removing drivers' maneuvers and time required to pay toll fees. Dedicated Short Range Communication (DSRC) is core technology that allows vehicle-to-roadside communication with the On-board 
Equipment (OBE) installed inside of vehicles and the Road-side Equipment (RSE) installed nearby the road. ETCS collects toll fees from moving vehicles by utilizing DSRC technology. This allows road users to pass the toll gate area without stopping. The ETCS service has widely been recognized and used by many road users.

Due to driving convenience, the number of vehicles equipped ETCS OBE is being increased. Those vehicles with ETCS OBE are running not only on freeways but also on urban highways. If the vehicles are treated as probe vehicles and a number of RSEs are equipped on roadsides, there would be a chance to collect valuable traffic information from urban highway networks. Conventional loop based systems, requiring high construction and maintenance cost, can be replaced with the DSRC based detection systems, as long as the accuracy of the data meet the system requirements.

This paper presents a study conducted to test feasibility of IR-DSRC as an alternative to collect speed information from an approach at a signalized intersection in urban traffic networks. A pair of sample speed data was prepared from field tests with the conventional loop and the IR-DSRC detection systems. They were compared to answer if the ones from IR-DSRC were statistically different from the others from the conventional loop-based detection systems.

\section{Wireless Communication in ITS}

Automated Traffic Surveillance and Control (ATSAC) is the traffic signal control systems in Los Angelis metropolitan area in the United States [5, 6]. Victor et al. [6] tested $900 \mathrm{MHz}$ wireless communication as an alternative to the conventional fiberbased communication utilized in ATSAC. They proposed that a server collect the raw data at the local controller level once a 0.5 seconds and found that each local controllers belonged to ATSAC was always connectable to the server at least 1.0 times a second despite heavy communication load. They employed a dynamic communication path searching algorithms to make it possible. Communication frequency level, 900 $\mathrm{MHz}$, however, is open to the public. Although it makes it easy to utilize wireless communication in the bandwidth, this makes the systems be vulnerable due to interruptions from conventional communication systems, such as laser scanners at convenience stores.

In recent decades, DSRC technology has been extensively introduced in the field of ITS. DSRC allows vehicles to communicate with RSE with either $5.8 \mathrm{G}-\mathrm{Hz}$ radio frequencies (RF) or infra-red (IR). Communication range of IR-DSRC can be adjusted from a couple of meters to several hundred meters based on its usage. Klein [7] employed IR-based wireless communication systems to deliver a video streaming data from field to traffic management center in Anaheim, CA. He reported that IR communication method can deliver a video streaming data at acceptable level and that this IR-based technology increases efficiency of the systems. Korea Transport Institute (KOTI) $[1,2]$ has developed a Wireless Interface Signals for Dynamic and Optimal Management (WISDOM) which performs as a single platform providing with traffic control scheme and information systems. Both IR-based and RF-based wireless communication systems were tested in their study. 


\section{Methodology}

Feasibility of IR-DSRC in measuring vehicle speed was tested through comparison between speed data measured by the IR-DSRC and the conventional loop systems. For the test, a pair of speed data was collected with the subjected detection systems. A set of test scenarios was developed, and based on the scenarios field data collection was made.

A field test site was carefully designed for simultaneous operation of two different vehicle detection systems. The westbound approach at a signalized intersection on Creek-side street in Anyang, Korea, was selected as a test site. Fig. 1 shows configuration of IR-DSRC and loop detection systems prepared for the test. A pair of IR-RSE antennas, numbered 1 and 2 as shown in the figure, was installed at $150 \mathrm{~m}$ upstream from a stop line. Distance between those antennas was set to $15 \mathrm{~m}$, which is critical to avoid overlapping of communication (detection) areas of IR-DSRC. The antennas were wired to RSE that gathers information from them.

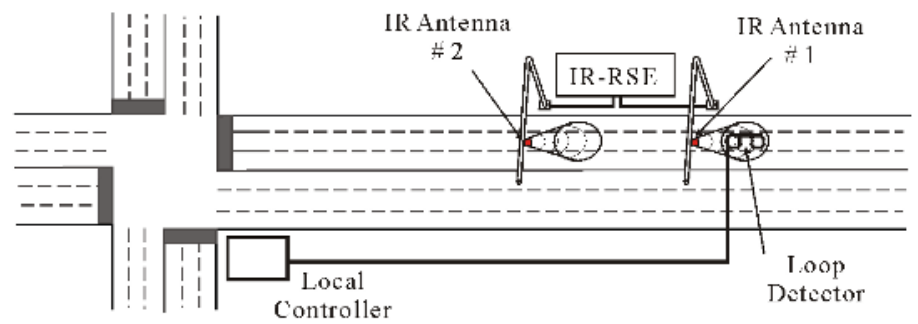

Fig. 1. Configuration of the field test site

A conventional dual loop detector was installed at the detection zone of IR-antenna numbered 1 (see Fig. 1). It consists of dual loops separating $4.3 \mathrm{~m}$ away (see Fig. 2). Speed data were measured on the middle lane of the subjected approach with the subject detection systems.

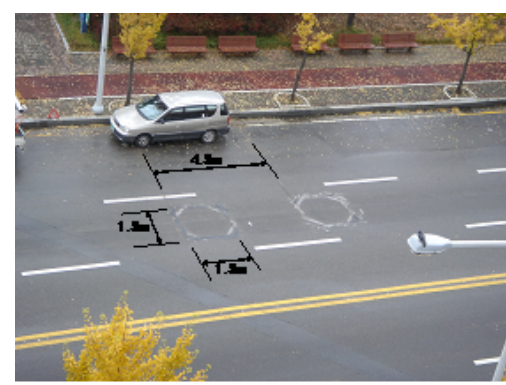

Fig. 2. Loop detectors at the field test site 
As depicted in Fig. 1, the detection area of IR-DSRC is longer than the one of the conventional dual loop systems. The long detection area always averages out the changes of speed. At certain speed levels, such changes of speed between the detection areas would not be trivial. It may influence the speed estimation significantly with IR-DSRC. In addition, there is a chance, in a successive vehicle arrival, that there is more than one vehicle exists between detection zones 1 and 2 .

Four vehicles (auto) were employed as probe vehicles for the study. Those vehicles were asked to pass the detection zone individually and in platoon. Table 1 presents the test scenarios developed for the study. For field tests, drivers driving probe vehicles were asked to maintain at certain speed levels. Speed data were simultaneously measured by the subject detection systems.

Table 1. Design of experimental tests and the number of samples collected

\begin{tabular}{|c|c|c|c|}
\hline Test types & $\begin{array}{l}\text { Intended run- } \\
\text { ning speed } \\
(\mathrm{km} / \mathrm{h})\end{array}$ & $\begin{array}{l}\text { The number of } \\
\text { tests performed }\end{array}$ & $\begin{array}{c}\text { The number } \\
\text { of Samples } \\
\text { collected }\end{array}$ \\
\hline \multirow{5}{*}{$\begin{array}{l}\text { Individual vehicle test } \\
\text { (single data sampling) }\end{array}$} & 20 & 4 & 4 \\
\hline & 30 & 4 & 4 \\
\hline & 40 & 8 & 8 \\
\hline & 50 & 4 & 4 \\
\hline & 60 & 4 & 4 \\
\hline \multirow{5}{*}{$\begin{array}{c}\text { Platoon test } \\
\text { (consecutive data sam- } \\
\text { pling; } \\
4 \text { vehicles in platoon) }\end{array}$} & 20 & 2 & 8 \\
\hline & 30 & 2 & 8 \\
\hline & 40 & 2 & 8 \\
\hline & 50 & 2 & 8 \\
\hline & 60 & 2 & 8 \\
\hline \multicolumn{3}{|c|}{ Total } & 64 \\
\hline
\end{tabular}

Individual vehicle tests reflect situations that vehicles drive with sufficient headways. This test was designed to check if the speed measured by IR-DSRC is at an acceptable level. Platoon tests reflect the situation that a platoon of vehicles enters a detection zone at once. This test was to check if the performance of IR-DSRC is able to detect successive vehicle arrival with short headways. The platoon based data collection was performed twice at each speed level.

The IR-DSRC detection systems compute the vehicle speed based on a distance between two detection areas and the difference of time that vehicle enters to each of those. The numerical computation can be expressed as Equation 1. Speed data measured by the IR-DSRC systems with Equation 1 were compared to the ones from the dual inductive loop detector. $S=(3,600 \times d) /\left\{1,000 \times\left(t_{1}-t_{0}\right)\right\}$ where, $S=$ speed $(\mathrm{km} / \mathrm{h}), d=$ distance between antennas $(\mathrm{m}), t_{0}=$ time when a vehicle was entered to the first IR-communication zone, and $t_{1}=$ time when a vehicle was entered to the second IR-communication zone. 
When each test trial finishes, the probe vehicles should be repositioned to the initial place for the next trial, and a test coordinator who is at outside of the vehicles nearby detection areas should search for a proper time to start the next trial. The coordinator was asked to find a situation (such as signal timing and queue length) that probe vehicles can maintain their intended speed. A single test trial producing four speed data with four probe vehicles took about 20 minutes.

\section{Analysis and Results}

Table 2 presents the data collected through a set of individual vehicle test trials. Total 24 test trials were made, and total 23 pairs of speed data were collected. A single case was dropped from the study - a speed data at $30 \mathrm{~km} / \mathrm{h}$ level was not detected with loop detector. The IR-DSRC data corresponding to it was thus discarded.

Table 2. Speed data collected from individual vehicle tests

\begin{tabular}{|c|c|c|c|c|c|c|}
\hline \multirow{2}{*}{$\begin{array}{c}\text { Intended } \\
\text { speed } \\
(\mathrm{km} / \mathrm{h})\end{array}$} & \multirow[b]{2}{*}{$\begin{array}{l}\text { Test } \\
\text { index }\end{array}$} & \multicolumn{2}{|c|}{ Loop } & \multicolumn{2}{|c|}{ IR-DSRC } & \multirow[b]{2}{*}{$\begin{array}{c}\text { Difference } \\
(\mathrm{km} / \mathrm{h})\end{array}$} \\
\hline & & $\begin{array}{c}\text { Time } \\
\text { (millisecond) }\end{array}$ & $\begin{array}{l}\text { Speed } \\
(\mathrm{km} / \mathrm{h})\end{array}$ & $\begin{array}{c}\text { Time } \\
\text { (millisecond) }\end{array}$ & $\begin{array}{l}\text { Speed } \\
(\mathrm{km} / \mathrm{h})\end{array}$ & \\
\hline \multirow{4}{*}{20} & 1 & $15: 15: 11.23$ & 22 & $15: 15: 13.23$ & 20 & -2 \\
\hline & 2 & $15: 15: 27.14$ & 20 & $15: 15: 29.08$ & 22 & +2 \\
\hline & 3 & $15: 15.53 .79$ & 20 & $15: 15: 56.01$ & 21 & +1 \\
\hline & 4 & $15: 16: 09.70$ & 16 & $15: 16: 12.41$ & 17 & +1 \\
\hline \multirow{3}{*}{$30^{1)}$} & 1 & $15: 20: 26.04$ & 29 & $15: 20: 27.49$ & 26 & -3 \\
\hline & 2 & $15: 20.59 .08$ & 28 & $15: 21: 00.52$ & 30 & +2 \\
\hline & 3 & $15: 21: 20.52$ & 28 & $15: 21: 22.11$ & 29 & +1 \\
\hline \multirow{8}{*}{40} & 1 & $15: 25: 16.60$ & 38 & $15: 25: 17.69$ & 34 & -4 \\
\hline & 2 & $15: 25: 26.19$ & 37 & $15: 25: 27.24$ & 39 & +2 \\
\hline & 3 & $15: 25: 52.53$ & 28 & $15: 25: 54.08$ & 29 & +1 \\
\hline & 4 & $15: 26: 11.35$ & 36 & $15: 26: 15.34$ & 38 & +2 \\
\hline & 5 & $15: 30: 51.22$ & 41 & $15: 30: 52.24$ & 36 & -5 \\
\hline & 6 & $15: 31: 02.99$ & 37 & $15: 31: 04.05$ & 39 & +2 \\
\hline & 7 & $15: 31: 21.42$ & 48 & $15: 31: 21.85$ & 41 & -7 \\
\hline & 8 & $15: 31: 33.84$ & 36 & $15: 31: 34.96$ & 38 & +2 \\
\hline \multirow{4}{*}{50} & 1 & $15: 34: 57.91$ & 53 & $15: 34: 58.77$ & 44 & -9 \\
\hline & 2 & $15: 35: 15.42$ & 31 & $15: 35: 16.88$ & 45 & +14 \\
\hline & 3 & $15: 35: 21.49$ & 47 & $15: 35: 22.38$ & 48 & +1 \\
\hline & 4 & $15: 35: 58.29$ & 44 & $15: 35: 59.31$ & 47 & +3 \\
\hline \multirow{4}{*}{60} & 1 & $15: 40: 11.83$ & 59 & $15: 40: 12: 49$ & 52 & -7 \\
\hline & 2 & $15: 40: 21.59$ & 61 & $15: 40: 22.24$ & 61 & 0 \\
\hline & 3 & $15: 42: 35.40$ & 55 & $15: 42: 36.18$ & 57 & +2 \\
\hline & 4 & $15: 42: 50.27$ & 53 & $15: 42: 51.04$ & 55 & +2 \\
\hline
\end{tabular}

1) One missing data (loop detector).

The detection time of IR-DSRC in Table 2 represents the vehicle entering time to the detection zone numbered 2 (see Fig. 1). Differences between speed data collected from IR-DSRC and loop detectors range from $-9 \sim+14 \mathrm{~km} / \mathrm{h}$. 
Table 3 presents the speed data collected through a set of platoon vehicle test trials. Total 40 vehicles in platoon were tested, and total 36 pairs of speed data were collected. Four cases considered in the test trial were dropped from the study - four speed data at $20 \mathrm{~km} / \mathrm{h}$ and $30 \mathrm{~km} / \mathrm{h}$ levels were not detected with loop detector. The IR-DSRC data corresponding to them were also discarded. Differences between speed data collected from IR-DSRC and loop detectors range from $-6 \sim+13 \mathrm{~km} / \mathrm{h}$.

Table 3. Speed data collected from platoon vehicle tests

\begin{tabular}{|c|c|c|c|c|c|c|}
\hline \multirow{2}{*}{$\begin{array}{c}\text { Intended } \\
\text { speed } \\
(\mathrm{km} / \mathrm{h})\end{array}$} & \multirow[b]{2}{*}{$\begin{array}{l}\text { Test } \\
\text { index }\end{array}$} & \multicolumn{2}{|c|}{ Loop } & \multicolumn{2}{|c|}{ IR-DSRC } & \multirow{2}{*}{$\begin{array}{c}\text { Difference } \\
(\mathrm{km} / \mathrm{h})\end{array}$} \\
\hline & & $\begin{array}{c}\text { Time } \\
\text { (millisecond) }\end{array}$ & $\begin{array}{l}\text { Speed } \\
(\mathrm{km} / \mathrm{h})\end{array}$ & $\begin{array}{c}\text { Time } \\
\text { (millisecond) }\end{array}$ & $\begin{array}{l}\text { Speed } \\
(\mathrm{km} / \mathrm{h})\end{array}$ & \\
\hline \multirow{6}{*}{$20^{1)}$} & \multirow{3}{*}{1} & $15: 48: 40.87$ & 20 & $15: 48: 42.95$ & 19 & -1 \\
\hline & & $15: 48: 43.48$ & 20 & $15: 48: 45.53$ & 21 & +1 \\
\hline & & $15: 48: 47.84$ & 18 & $15: 48.50 .34$ & 19 & +1 \\
\hline & \multirow{3}{*}{2} & $16: 10: 34.01$ & 20 & $16: 10: 36.15$ & 18 & -2 \\
\hline & & $16: 10: 40.00$ & 17 & $16: 10: 40.14$ & 20 & +3 \\
\hline & & $16: 10: 42.37$ & 16 & $16: 10: 42.61$ & 18 & +2 \\
\hline \multirow{6}{*}{$30^{2)}$} & \multirow{4}{*}{1} & $15: 54: 45.11$ & 27 & $15: 54: 45.65$ & 25 & -2 \\
\hline & & $15: 54: 46.55$ & 27 & 15:54:48.05 & 29 & +2 \\
\hline & & $15: 54.48 .57$ & 27 & $15: 54: 50.23$ & 25 & -2 \\
\hline & & 15:54:50.13 & 27 & 15:54:51.68 & 28 & +1 \\
\hline & \multirow{2}{*}{2} & 16:15:08.55 & 30 & $16: 15: 09.97$ & 26 & -4 \\
\hline & & $16: 15: 10.52$ & 27 & 16:15:11.97 & 29 & +2 \\
\hline \multirow{8}{*}{40} & \multirow{4}{*}{1} & 16:00:22.83 & 40 & 16:00:23.87 & 36 & -4 \\
\hline & & 16:00:24.17 & 37 & $16: 00: 25.23$ & 38 & +1 \\
\hline & & 16:00:25.38 & 38 & $16: 00.26 .54$ & 37 & -1 \\
\hline & & 16:00:26.64 & 37 & 16:00:27.78 & 39 & +2 \\
\hline & \multirow{4}{*}{2} & 16:20:14.39 & 38 & 16:20:15.33 & 34 & -4 \\
\hline & & $16: 20: 16.32$ & 38 & $16: 20: 17.43$ & 39 & +1 \\
\hline & & $16: 20: 17.50$ & 37 & $16: 20: 18.57$ & 39 & +2 \\
\hline & & 16:20:18.39 & 38 & $16: 20: 19: 53$ & 40 & +2 \\
\hline \multirow{8}{*}{50} & \multirow{4}{*}{1} & 16:05:10.13 & 48 & 16:05:11.02 & 43 & -5 \\
\hline & & 16:05:11.50 & 48 & $16: 05: 12.36$ & 48 & 0 \\
\hline & & 16:05:12.63 & 47 & 16:05:13.54 & 48 & +1 \\
\hline & & 16:05:14.34 & 45 & 16:05:15.31 & 46 & +1 \\
\hline & \multirow{4}{*}{2} & 16:25:03.78 & 50 & $16: 25: 04.60$ & 44 & -6 \\
\hline & & 16:25:05.55 & 49 & 16:25:06.39 & 48 & -1 \\
\hline & & 16:25:06.76 & 46 & $16: 25: 07.73$ & 46 & 0 \\
\hline & & $16: 25: 07.83$ & 45 & $16: 25: 08.75$ & 47 & +2 \\
\hline \multirow{8}{*}{60} & \multirow{4}{*}{1} & 16:32:47.64 & 58 & $16: 32: 48.28$ & 55 & -3 \\
\hline & & 16:32:48.91 & 58 & $16: 32: 49.61$ & 61 & +3 \\
\hline & & $16: 32: 50.12$ & 59 & 16:32:50.84 & 60 & +1 \\
\hline & & 16:32:54.55 & 44 & $16: 32: 52.06$ & 57 & +13 \\
\hline & \multirow{4}{*}{2} & $16: 37: 46.27$ & 59 & $16: 37: 46.95$ & 54 & -5 \\
\hline & & $16: 37: 47.84$ & 58 & $16: 37: 48.54$ & 59 & +1 \\
\hline & & 16:37:49.00 & 54 & $16: 37: 49.72$ & 57 & +3 \\
\hline & & 16:37:49.97 & 53 & $16: 37: 50.76$ & 56 & +3 \\
\hline
\end{tabular}

1) Two missing data (loop detector), Two missing data (loop detector) 


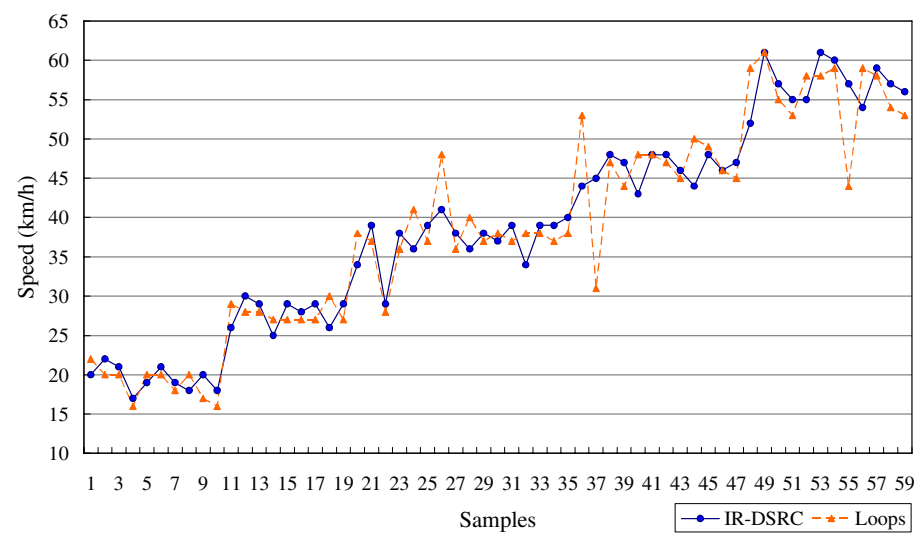

Fig. 3. Comparison between speeds from the loop and the IR-DSRC based detectors

Sample data from the IR-DSRC and conventional loop detectors were graphically compared (see Fig. 3). The comparison results visualize that those samples are in similar shape with higher fluctuation with the loop detector than the one with IRDSRC. A set of statistical tests was performed to check if those samples were close enough to consider them as statistically identical.

To check whether those samples share unique features in their distribution, a paired $t$-test was conducted at $95 \%$ significant level. Table 4 presents the test results. The results support that the speed data collected from the IR-DSRC systems are statistically identical to the ones from the conventional loop detectors - rejection of null hypothesis.

$H_{0}$ : Samples from conventional loop and IR-DSRC are from same population

$H_{a}$ : Samples from conventional loop and IR-DSRC are from different populations

Table 4. Results of a paired $t$-test performed at 95\% significant level

\begin{tabular}{|c|c|c|c|}
\hline \multicolumn{3}{|c|}{ Summary } & $\begin{array}{l}\text { Difference between speeds meas- } \\
\text { ured by loops and IR-DSRC }\end{array}$ \\
\hline \multirow{5}{*}{$\begin{array}{c}\text { Paired } \\
\text { Difference } \\
\mathrm{s}\end{array}$} & \multicolumn{2}{|c|}{ Average } & 0.22 \\
\hline & \multicolumn{2}{|c|}{ Std. Deviation } & 3.878 \\
\hline & \multicolumn{2}{|c|}{ Std. Error } & 0.505 \\
\hline & \multirow{2}{*}{$\begin{array}{c}\text { Significant range } \\
\text { At } 95 \% \text { significan } \\
\text { ce }\end{array}$} & Lower Limit & -0.79 \\
\hline & & Upper Limit & 1.23 \\
\hline \multicolumn{3}{|c|}{$t$} & 0.436 \\
\hline \multicolumn{3}{|c|}{$d f$} & 58 \\
\hline \multicolumn{3}{|c|}{ Significance (two-tailed) } & 0.664 \\
\hline
\end{tabular}


It is necessary to test the performance of the detection systems at various traffic flow conditions. The speed data were grouped into five different: $20 \mathrm{~km} / \mathrm{h}, 30 \mathrm{~km} / \mathrm{h}, 40$ $\mathrm{km} / \mathrm{h}, 50 \mathrm{~km} / \mathrm{h}$, and $60 \mathrm{~km} / \mathrm{h}$. At each level, a statistical test, a goodness-of-fit test, was conducted by designing the hypothesis as follows:

$H_{0}$ : Speeds measured by Loops $\neq$ Speeds measured by IR-DSRC

$H_{a}$ : Speeds measured by Loops $=$ Speeds measured by IR-DSRC

Table 5 summarizes the test results. It can be concluded from the results that the speed data collected from the IR-DSRC systems are statistically identical to the ones from the conventional loop detectors at $95 \%$ significant level. Same result applies to all five speed levels.

Table 5. Results of goodness-of-fit tests at different speed levels

\begin{tabular}{|c|c|c|c|c|}
\hline Speed $(\mathrm{km} / \mathrm{h})$ & $\chi^{2}$ & $d f$ & $\chi^{2}(d . f, 0.05)$ & $H_{0}$ \\
\hline 20 & 1.085587 & 8 & 21.9550 & Reject \\
\hline 30 & 1.738862 & 8 & 21.9550 & Reject \\
\hline 40 & 4.109437 & 15 & 32.8013 & Reject \\
\hline 50 & 7.956877 & 11 & 26.7569 & Reject \\
\hline 60 & 5.176488 & 11 & 26.7569 & Reject \\
\hline
\end{tabular}

\section{Conclusion}

In the past decades, wireless communication technology has been introduced in the field of ITS, and its applicability has been widely expending. In this study, feasibility of the IR-DSRC based detection systems in measuring vehicle speed was tested as a possible alternative of the conventional loop based detection systems. In practice, it would be advantageous to have the less expensive traffic surveillance systems requiring inexpensive maintenance cost. The IR-DSRC based technology highlights less initial construction and repairing costs.

Based on the sample speed data sets collected from the field test, it was found that the speed data from the IR-DSRC detection systems were statistically identical to the ones from the loop based systems at $95 \%$ confidence level. It supports to conclude that the IR-DSRC based system is feasible in measuring vehicle speeds in urban network. It was experienced that the IR-DSRC systems detected $100 \%$ of all test trials. However, the loop based systems did not detect some of vehicle data. The limitation of this study is the small number of sample data due to the test-consuming field test procedure. Further studies with the increased number of samples are recommended.

\section{References}

1. Development of Next Generation Traffic Signal Control System Utilizing Wireless Communications (Phase 1): Final Report, National Transportation Core Technology Research and Development, The Korea Transport Institute, 2004 
2. Development of Next Generation Traffic Signal Control System Utilizing Wireless Communications (Phase 2): Final Report, National Transportation Core Technology Research and Development, Korea Transport Institute, Transportation, 2005

3. Oh Y.T., Kim N.S., Kim S.H., Song K.H., A study of Relative Feeder-cable Length and Vehicle Detection Length of Loop Detector, J. of Korean Society of Transportation, Vol. 22-3, pp85 94, 2004

4. Enhancing Reliance of Inductive Loop based Traffic Data, National Police Agency, 2003

5. Los Angeles Spread Spectrum Radio Traffic Signal Interconnect Practical Lessons Learned Evaluation Report, Final Report, Booz-Allen \& Hamilton, 1999

6. Victor O.K., Li S.S., Chan T.K. and Zhuge L., Los Angeles Spread Spectrum Radio Traffic Signal Interconnect Evaluation Task: Final Report on Full Deployment, 1998

7. Klein L.A., Mobile Surveillance and Wireless Communication Systems Field Operational Test, Final Report, California PATH, 1999 